\title{
ИССЛЕДОВАНИЕ ПРОБЛЕМЫ ОБРАЗОВАНИЯ КИТАЙСКИХ МИГРАНТОВ НА ДАЛЬНЕМ ВОСТОКЕ РОССИИ ${ }^{1}$
}

\section{STUDY OF THE EDUCATION PROBLEM OF CHINESE MIGRANTS IN THE FAR EAST OF RUSSIA}

\section{Lyu Xiaojiao}

Summary: The article examines the features and key problems of the education of Chinese immigrants in the Russian Far East. Special attention is paid to the difficulties that Chinese students face in their first year of study. Problems with learning Russian are also indicated. Particular emphasis is placed on the psychological problems of adapting to a new environment. The study substantiated recommendations for educational institutions and teaching staff, which will create favorable conditions for the adaptation of Chinese migrants in the learning process.

Keywords: training, PRC, Russia, migrants, adaptation.

\author{
Люй Сяоцзяо \\ Старший преподаватель, Хэйхэский университет \\ 84688767@q9.com
}

Аннотация: В статье проведено исследование особенностей и ключевых проблем образования китайских иммигрантов на Дальнем Востоке России. Отдельное внимание уделено трудностям, с которыми китайские студенты сталкиваются на первом курсе обучения. Также обозначены препятствия с обучением русскому языку. Особый акцент сделан на психологических проблемах адаптации к новой обстановке. В ходе исследования обоснованы рекомендации для учебных заведений и преподавательского состава, которые позволят создать благоприятные условия интеграции китайских мигрантов в процесс обучения.

Ключевые слова: обучение, КНР, Россия, мигранты, адаптация.
Д инамические процессы глобализации и стремительные темпы развития научно-технического прогресса пронизывают не только экономичеотношения, но и всю образовательную систему. Вследствие этого в современном мире большую популярность приобретают международные связи в сфере науки и образования [1].

Для достижения цели успешного управления учебным и воспитательным процессом обучающихся, прибывших из-за границы, необходимо учитывать, что с поступлением в учебное заведение они попадают в необычную для них социальную, языковую и национальную среду, к которой им предстоит адаптироваться. В связи с этим интернационализация современных образовательных систем актуализирует проблему наиболее безболезненного включения иностранных студентов в чуждую им действительность незнакомой страны.

Особую важность данная проблематика приобретает для обучения китайских мигрантов на Дальнем Востоке России, поскольку за последние 5 лет количество получающих образование в российских вузах граждан Китая, увеличилось практически в два раза и достигло отметки 30 тыс. человек [2].

Каждый китайский студент, поступающий на обуче- ние в учебные заведения России, обладает уникальной ментальностью, отражает особенности своей страны, характеризуется определенным психологическим состоянием, а также имеет своеобразное восприятие новой для него социокультурной среды. Эти обстоятельства необходимо принимать во внимание в процессе организации процесса обучения и воспитания студентов-иностранцев. Не подлежит сомнению тот факт, организация эффективной адаптации китайских иммигрантов будет способствовать их быстрому включению в учебную среду, облегчит знакомство и усвоение ключевых норм и правил поведения в новом коллективе, позволит наиболее безболезненно преодолеть «языковый барьер» и усилит чувство академического равноправия.

Однако, в процессе адаптации китайских мигрантов к новым социокультурным условиям обучения в учебных заведениях России возникает ряд трудностей, которые снижают эффективность образовательного процесса и соответственно требуют всесторонних психолого-педагогических исследований.

Таким образом, указанные обстоятельства обуславливают своевременность, теоретическую и практическую значимость темы данной статьи.

Особенности адаптации обучающихся в новом образо-

Данная статья публикуется в рамках научно-исследовательского проекта основного операционного расхода вузов провинции Хэйлунцзян 2018 г. на тему «Изучение изменений истории и нынешнего состояния китайских мигрантов на фоне районов в России». Проект 2018-KYYWF-1283. 
вательном пространстве принимающих стран составляют предмет изучения широкого спектра наук, в состав которых входят гуманитарные, педагогические, технические. Вследствие этого различные аспекты обучения иностранных студентов исследуются современными авторами.

Так, психолого-педагогические проблемы первого года обучения, особенности социальной и бытовой адаптации рассмотрены в трудах Bittencourt, Tiago; Johnstone, Christopher; Adjei, Millicent; Seithers.

Отличительные черты организации обучения студентов-иностранцев по различным специальностям нашли свое отражение в работах Тугаревой В.В., Сушко Ю.В., Береговой О.А., Лопатиной С.C., Alina Schartner.

В последнее время в современной педагогической науке среди моделей помощи иностранным студентам в процессе их обучения особую популярность приобретает парадигма сопровождения, которая разрабатывается Цыплаковой С.А., Быстровой H.B., Jiexiu Chen.

Анализ литературы, в которой раскрываются проблемы обучения иностранных студентов свидетельствует, что несмотря на широкий круг исследований, в научном и практическом плане эти вопросы на сегодня остаются малоисследованными.

Так, недостаточно проработанной является система уровней адаптации иностранных граждан, к образовательному пространству принимающей страны. Также отдельного внимания заслуживают вопросы, связанные с интеграцией иностранных студентов, как в рамках учебной деятельности, так и при проведении внеаудиторных мероприятий, что призвано способствовать ускорению данного процесса, а также нацелено на формирование языковой и социокультурной компетенции.

Итак, с учетом вышеизложенного, цель статьи заключается в исследовании проблемы образования китайских мигрантов на Дальнем Востоке России.

Обновление всех сфер жизни в условиях рыночной экономики, построение информационного общества на принципах гуманизма обуславливает усиленное внимание ученых и педагогов к проблеме подготовки будущих специалистов, формированию социальной и трудовой активности, а также профессионально важных качеств на основе деятельностнокомпетентностного подхода к практико-ориентированному образованию.

Обозначенные требования предопределяют необходимость акцентирования особого внимания на профессиональной подготовке китайских иммигрантов, поскольку большинство из них с приездом в Россию сталкивается со множеством трудностей как физиологического (привыкания к климату, кухне), так и социально-психологического характера (приспособление к бытовым условиям, нормам поведения и требованиям учебной деятельности).

Также, следует отметить, что традиционно большинство иностранных студентов перед вступлением на первый курс российских вузов обучаются на подготовительных факультетах, в рамках которых созданы все необходимые условия для успешной адаптации и формирования адекватных практик поведения в условиях иноязычной социопедагогической и социокультурной среды. Подготовка на таких факультетах позволяет достичь преемственности методов, форм, направленности учебно-воспитательного процесса вуза в процессе прохождения основного этапа обучения, а главное - значительно сокращает время адаптации иностранцев к новым социокультурным условиям страны обучения.

Как свидетельствует практика, китайские иммигранты, которые стремятся получить образование в учебных заведениях Дальнего Востока России, в большинстве своем, не обучаются на подготовительных курсах и факультетах, либо по причине их отсутствия, либо в результате слабой информированности и не высокой активности учебных заведений в процессе проведения разъяснительной работы среди будущих студентов. В связи с этим, на первом курсе китайские иммигранты зачастую сталкиваются с рядом следующих трудностей:

1. физиологические трудности, связанные с перестройкой личности, эмоциональным напряжением и т.д.;

2. учебно-познавательные трудности, возникновение которых обусловлено недостаточной языковой подготовкой, необходимостью приспособиться к отличиям в образовательном процессе и адаптироваться к новым требованиям и методам контроля;

3. социокультурные проблемы, которые находят свое проявление вследствие требования освоения нового социального и культурного пространства вуза; преодоления языкового барьера в решении коммуникативных проблем. Изменения условий и быта, отсутствие привычного комфорта нередко мешают студентам сосредоточиться на учебе. Культурные традиции и региональные особенности играют важную роль в формировании адаптационных навыков у иностранных студентов.

Отдельный акцент необходимо сделать на том, что успешное обучение китайских иммигрантов предполагает освоение на высоком уровне русского языка, что даст возможность сформировать профессионально значимые навыки и умения.

Большинство китайских студентов, поступающих в учебные заведения на Дальнем Востоке России считают, что для повседневного общения их уровень знаний русского языка является достаточным, но при этом они отмечают, что имеющихся навыков критически не хватает для учебного процесса. Кроме того, сложность процесса 
адаптации к обучению в дальневосточных вузах заключается в том, что у студента происходит перестройка всей системы ценностно-познавательных ориентаций личности, усваиваются новые способы познавательной деятельности, формируются определенные типы и формы межличностных отношений [3].

Также, по мнению автора, целесообразно обратить внимание на ряд психологических проблем, с которыми сталкиваются китайцы-иммигранты в процессе обучения, основными из них являются следующие:

- проблемы, вызванные вхождением в новый коллектив, необходимостью приспособления к непривычным бытовым условиям, трудности освоения новых традиций и норм поведения, а также способов и методом коммуникации с окружающими;

- проявление этнических и культурных предубеждений, которые находят свое проявление в виде бытового расизма и национализма;

- сложные и зачастую непрогнозируемые ситуации в учебной, социокультурной, ежедневной среде общения, которые приводят к недопонимаю, психологическим проблемам и значительно затрудняют возможность реализации личностных мотивов, удовлетворение поведенческих, эмоциональных, потребностей;

- неадаптивные реакции, которые приводят к ухудшению самочувствия, повышенной тревожности, отчуждению от коллектива, межличностным и внутриличностным конфликтам. Все это влечет за собой снижение успеваемости, потерю интереса и смысла продолжать обучение и профессионально развиваться.

Обозначенные проблемы, по мнению автора, могут и должны быть надлежащим образом решены средствами педагогической практики, реализуемой как со стороны учебных заведений, так преподавателей.

С педагогической точки зрения учебным заведениям Дальнего Востока России для создания благоприятных условий адаптации китайских мигрантов в процессе обучения и преодоления выше обозначенных трудностей необходимо предпринять ряд следующих мер:
1. Создать соответствующую организационную базу, которая будет позволять реализовать набор, сопровождение, регистрацию граждан Китая для обучения в России. Эту функцию целесообразно возложить на деканат факультета подготовки иностранных граждан, структурные подразделения которого должны быть нацелены на выполнение указанных задач.

2. Организовать качественную и непрерывную языковую подготовку, начиная с подготовительного отделения, деятельность которого должна быть направлена на обеспечение овладения китайцами русским языком и профессиональной терминологией на уровне, достаточном для дальнейшего обучения, а также возможность совершенствовать коммуникативные навыки путем изучения отдельных дисциплин в течение всего периода обучения без потерь в профессиональной подготовке.

3. Свободный доступ к образовательным ресурсам учебного заведения. Например, в университете целесообразно разработать сайт персональных обучающих систем, где каждый студент, пройдя соответствующую регистрацию, получает доступ к ресурсам учебного курса, может задать вопрос преподавателю, получить консультацию, а также выполнить контрольные задания и видеть результаты оценивания.

4. Привлечение иностранных студентов к общественной жизни учебного заведения, проведение культурных мероприятий.

Таким образом, резюмируя результаты проведенного исследования можно сделать следующие выводы.

Китайские мигранты в процессе прохождения обучения на Дальнем Востоке России, особенно в первые годы, сталкиваются со многими проблемами, касающимися новых бытовых условий, процессов адаптации к обществу и особенностям учебной деятельности. Задача педагогов и образовательного учреждения в целом в этой ситуации заключается в поиске тех форм, методов и способов организации работы, которые будут способствовать облегчению привыкания и интеграции студента-иностранца к новой среде.

\section{ЛИТЕРАТУРА}

1. Bittencourt, Tiago «We See the World Different Now»: Remapping Assumptions About International Student Adaptation // Journal of studies in international education. 2021. Number 1; pp 35-50.

2. Intercultural transitions in higher education: international student adjustment and adaptation / Alina Schartner, Tony Young. Edinburgh: Edinburgh University Press, 2020. $195 \mathrm{p}$.

3. Zhou, Jiming How first-year students perceive and experience assessment of academic literacies // Assessment \& evaluation in higher education. 2020. Volume 45: Issue 2; pp 266-278. 